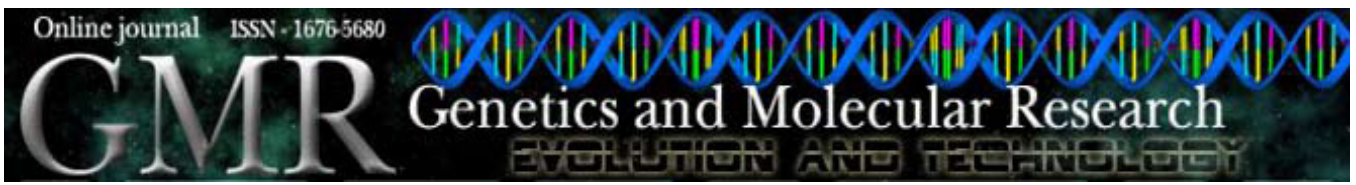

$\underline{\text { Short Communication }}$

\title{
Isolation and characterization of eight polymorphic microsatellite loci for the coconut pest, Brontispa longissima (Coleoptera: Hispidae)
}

\author{
C.L. Ma ${ }^{1}$, H.L. Wu ${ }^{1}$, H.Y. Hu ${ }^{1}$, X. Wu ${ }^{1}$, G.C. $\mathrm{Ma}^{2}$, Y.G. Fu ${ }^{2}$ and Z.Q. Peng ${ }^{2}$ \\ ${ }^{1}$ Key Laboratory of Biotic Environment and Ecological Safety in Anhui Province, \\ College of Life Sciences, Anhui Normal University, Wuhu, Anhui, China \\ ${ }^{2}$ Key Laboratory of Monitoring and Control of Tropical Agricultural and \\ Forest Invasive Alien Pests, Ministry of Agriculture, Environment and Plant \\ Protection Institute, Chinese Academy of Tropical Agricultural Sciences, \\ Danzhou, Hainan, China
}

Corresponding author: H.Y. Hu / Z.Q. Peng

E-mail: haoyuanhu@126.com / lypzhq@163.com

Genet. Mol. Res. 10 (1): 429-432 (2011)

Received October 4, 2010

Accepted January 10, 2011

Published March 15, 2011

DOI 10.4238/vol10-1gmr1008

\begin{abstract}
Brontispa longissima is one of the most serious insect pests of coconut in Southeast Asia; it was first discovered on Hainan Island in June 2002. Despite the economic risk associated with this pest, genetic aspects of the invasion process have remained relatively unexplored. Using microsatellite markers, we investigated the population structure, genetic variability and pattern of invasion in various geographic populations. The methodology was based on a modified biotin-capture method. Eight polymorphic microsatellite loci were isolated and characterized for the pest. The allele number per locus varied from 2 to $3(\mathrm{~N}=30)$. The expected and observed heterozygosities of the eight loci ranged from 0.042 to 0.509 and from 0.042 to 0.963 , respectively. Although the frequency of polymorphisms was not very high in this population, the microsatellite loci that were isolated will be useful for investigating the genetic
\end{abstract}


diversity and migration routes of $B$. longissima populations.

Key words: Beetle; Brontispa longissima; Microsatellite markers; Polymorphism

Simple sequence repeats (SSRs) or microsatellite DNA, as one of the most powerful molecular markers, can be used to study intra- or interspecific variation and genetic structure in biological populations. Recently, some articles have analyzed the invasion process of insect pests, using SSR markers (Simon et al., 2007; De Barro et al., 2008; Wilson et al., 2009). Brontispa longissima (Gestro) (Coleoptera: Hispidae) is one of the most serious insect pests of coconut in Southeast Asia. No SSR markers have been reported for the pest and the insects of the Hispidae.

$B$. longissima is a palmivorous insect, and both larvae and adults attack the leaves of palms, including coconut. The leaves finally tear leaving a ragged appearance also from secondary fungal infections. The infested spears could rot and the palms, especially the young ones, would die from severe infestation (Stapley, 1980). Although this insect is considered to be native to Indonesia and Papua New Guinea, it has recently invaded South East Asia, Australia (Darwin, Broome, Moa Island, Cooktown, Cairns, Innisfail, Marcoola, and Townsville), many Pacific Islands, Malaysia, Singapore, Cambodia, Laos, Thailand, Vietnam, the Maldives, Philippines, Myanmar, and China (Hainan, Guangdong and Taiwan Provinces, with the Hainan Islands being the most affected) (Asia-Pacific Forest Invasive Species Network). In China, the pest was first discovered in Haikou City in June 2002 and shortly afterward in Sanya City (Lu et al., 2008).

Samples of $B$. longissima were collected within Hainan province. All samples were preserved in $>95 \%$ ethanol and stored at $-20^{\circ} \mathrm{C}$. More than one hundred samples were collected from Hainan Province. Genomic DNA was extracted from ethanol-preserved samples using a standard proteinase K/phenol extraction protocol (Sambrook and Russell, 2001).

The methodology was based on a modified biotin-capture method (Hamilton et al., 1999). Following Sau3AI (TaKaRa) digestion of genomic DNA, fragments of 400-1000 bp were obtained and purified using the Agarose Gel Purification Kit (Axygen). The purified fragments were then ligated to two adaptor oligonucletides (adaptor A: 5'-GGCCAGAGACCCCAAGCTTCG; adaptor B: 5'-phosphate-GATCCGAAGCTTGGGGTCTCTGGCC) using a DNA Ligation Kit (TaKaRa). The DNA was hybridized with biotinylated oligonucletide $(\mathrm{AC})_{12},(\mathrm{AG})_{12}$, and (ACAT) $)_{6}$ probes (Sangon). These heteroduplexes were then selected using Streptavidin Magnetic Particles (Roche) and the DNA was enriched by polymerase chain reaction (PCR) with adaptor A as forward and reverse primers. Microsatellite-enriched DNA fragments were ligated into PMD-18T vector (TaKaRa), transformed to DH5a cells and plated onto Luria-Bertani agar medium with ampicillin. In total, 260 positive clones were selected and sequenced on the ABI PRISM 3730 automated sequencer (Applied Biosystems). A total of 99 primer pairs were designed based on nucleotide sequence regions flanking microsatellites using the Oligo 6 software. Only 20 sets of primers that gave consistent and specific PCR products were used for further polymorphism analysis, and the others were rejected because of the absence of PCR product or nonspecific amplification. Polymorphism of microsatellite loci were analyzed using $8 \%$ denaturing polyacrylamide gels according to the method of $\mathrm{Wu}$ et al. (2008) and microsatellite loci proved to be polymorphic.

Tests of significant deviation from Hardy-Weinberg equilibrium (HWE) and linkage disequilibrium were performed using GENEPOP, version 3.4 (Raymond and Rousset, 1995). Micro-Checker version 2.2.3 (van Oosterhout et al., 2004), was used to test for the presence 
of null alleles. The CERVUS 2.0 program (Marshall et al., 1998) was used to determine allele frequency and observed and expected heterozygosities (Nei, 1987).

The numbers of alleles, size ranges, and observed and expected heterozygosities were shown in Table 1. The number of alleles per locus varied from 2 to 3 and expected and observed heterozygosities ranged from 0.042 to 0.509 and from 0.042 to 0.963 , respectively. No significant linkage disequilibrium among all pairwise comparisons of microsatellite loci was detected. Three loci (BL4, BL7, BL8) were discovered to be significantly deviated from HWE $(\mathrm{P}<0.05)$. The reasons accounting for deviation from HWE may be a population bottleneck effect or null alleles. Considering the fact that the species populated Hainan Province several years ago, population bottleneck rather than null allele likely accounts for the three deviations from HWE detected in the current study. Population bottlenecks affect many invasive species because they frequently experience founding effects that reduce genetic variability, but paradoxically, invasive species still manage to successfully establish and adapt to new environments (Chen et al., 2006). However, the effects of bottlenecks may be countered by the occurrence of multiple introductions, high reproductive rates, and subsequent migration between locally bottlenecked populations that are genetically differentiated (Frankham, 2005). Populations of recently introduced aliens often show lower genetic diversity than do native populations (Puillandre et al., 2008). This reduced genetic diversity in nonnative ranges is likely to be the result of a founder effect whereby the introduced individuals carry only a small fraction of genetic diversity of the source populations (Lockwood et al., 2007). Therefore, the relative short time for the species invasion into Hainan might have also contributed to the low allele diversity screened in this study. Although the polymorphisms were not very high due to a population bottleneck, the microsatellite loci isolated in this study will be useful for investigating the genetic diversity and the route of transmission in B. longissima populations.

\begin{tabular}{|c|c|c|c|c|c|c|c|c|}
\hline$\overline{\text { Locus }}$ & Primer sequences $\left(5^{\prime}-3^{\prime}\right)$ & Repeat motif & $T_{a}\left({ }^{\circ} \mathrm{C}\right)$ & $\begin{array}{l}\text { Size range of } \\
\text { alleles (bp) }\end{array}$ & $\begin{array}{l}\text { No. of } \\
\text { alleles }\end{array}$ & $H_{O}$ & $\overline{H_{E}}$ & GenBank \\
\hline BL1 & $\begin{array}{l}\text { F: GCAGACACCCACACATACAT } \\
\text { R: AGGAGTGCGTCTGTGGCTTC }\end{array}$ & $(\mathrm{CA})_{6}$ & 55 & 203-239 & 3 & 0.633 & 0.459 & HM752771 \\
\hline BL2 & $\begin{array}{l}\text { F: TTGTTCTGTCTCTTTCCT } \\
\text { R: ACGGAGAGGTCTTATTGC }\end{array}$ & $(\mathrm{CT})_{4} \mathrm{GT}(\mathrm{CT})_{5}$ & 51 & $278-282$ & 2 & 0.167 & 0.155 & HM752772 \\
\hline BL3 & $\begin{array}{l}\text { F: AAACCCTGGCGGATGAAA } \\
\text { R: AATCGCACCCGACTGACC }\end{array}$ & $(\mathrm{AC})_{15}$ & 53 & $329-333$ & 2 & 0.474 & 0.508 & HM752773 \\
\hline BL4 & $\begin{array}{l}\text { F: TACCCTGACACCATACTTTAC } \\
\text { R: TGGAGCAAGCAAGGAGCATA }\end{array}$ & $(\mathrm{CATA})_{6}$ & 58 & $249-253$ & 2 & 0.963 & 0.509 & HM752774 \\
\hline BL5 & $\begin{array}{l}\text { F: GTCTGAGTGTATGTATG } \\
\text { R: CGAATCCAGGCGTGACTTTT }\end{array}$ & $(\mathrm{GT})_{9}$ & 56 & $180-184$ & 2 & 0.448 & 0.390 & HM752775 \\
\hline BL6 & $\begin{array}{l}\text { F: TTGGTACTGGTAATGAAATG } \\
\text { R: CCACTGGTTAATTCGTCTGA }\end{array}$ & $(\mathrm{AC})_{7}$ & 50 & $290-314$ & 2 & 0.538 & 0.507 & HM752776 \\
\hline BL7 & $\begin{array}{l}\text { F: AATTCCCACTCAAACTCG } \\
\text { R: GTCGTGTCCCGTCATAGA }\end{array}$ & $(\mathrm{GT})_{14}$ & 50 & $262-266$ & 2 & 0.042 & 0.042 & HM752777 \\
\hline BL8 & $\begin{array}{l}\text { F: AGCCTATGCGTTATTCTGAT } \\
\text { R: GAAGGTGATTATGTTGATGG }\end{array}$ & $(\mathrm{ACAT})_{3}$ & 51 & $271-275$ & 2 & 0.207 & 0.508 & HM752778 \\
\hline
\end{tabular}

$T_{\mathrm{a}}$ is the annealing temperature; $H_{O}$ and $H_{E}$ are the observed and expected heterozygosities, respectively.

\section{ACKNOWLEDGMENTS}

Research supported by the Open Fund of Key Laboratory of Monitoring and Control of Tropical Agricultural and Forest Invasive Alien Pests, Ministry of Agriculture (\#MACKL0904), 
by the Special Fund for Agro-Scientific Research in the Public Interest (\#200803023 and \#200903026-5), partially by Funds from the National Basic Research and Development Program (\#2009CB119200), and the National Key Technologies Research and Development Program of China (\#2006BAD08A18). All experiments reported here comply with the current laws of China.

\section{REFERENCES}

Chen YH, Opp SB, Berlocher SH and Roderick GK (2006). Are bottlenecks associated with colonization? Genetic diversity and diapause variation of native and introduced Rhagoletis completa populations. Oecologia 149: 656-667.

De Barro P, Hidayat S, Frohlich D, Subandiyah S, et al. (2008). A virus and its vector, pepper yellow leaf curl virus and Bemisia tabaci, two new invaders of Indonesia. Biol. Invas. 10: 411-433.

Frankham R (2005). Resolving the genetic paradox in invasive species. Heredity 94: 385.

Hamilton MB, Pincus EL, Di Fiore A and Fleischer RC (1999). Universal linker and ligation procedures for construction of genomic DNA libraries enriched for microsatellites. Biotechniques 27: 500-507.

Lockwood J, Hoopes M and Marchetti M (2007). Invasion Ecology. Blackwell Publishing, Oxford.

Lu B, Tang C, Peng Z, La Salle J, et al. (2008). Biological assessment in quarantine of Asecodes hispinarum Boucek (Hymenoptera: Eulophidae) as an imported biological control agent of Brontispa longissima (Gestro) (Coleoptera: Hispidae) in Hainan, China. Biol. Cont. 45: 29-35.

Marshall TC, Slate J, Kruuk LE and Pemberton JM (1998). Statistical confidence for likelihood-based paternity inference in natural populations. Mol. Ecol. 7: 639-655.

Nei M (1987). Molecular Evolutionary Genetics. Columbia University Press, New York.

Puillandre N, Dupas S, Dangles O and Zeddam J (2008). Genetic bottleneck in invasive species: the potato tuber moth adds to the list. Biol. Invas. 10: 319-333.

Raymond M and Rousset F (1995). Genepop (version 3.4): population genetics software for exact tests and ecumenicism. J. Hered. 86: 248-249.

Sambrook J and Russell D (2001). Molecular Cloning: a Laboratory Manual. 3rd edn. Cold Spring Harbor Laboratory, New York.

Simon B, Cenis JL and De La Rua P (2007). Distribution patterns of the Q and B biotypes of Bemisia tabaci in the Mediterranean Basin based on microsatellite variation. Ent. Exp. Appl. 124: 336.

Stapley J (1980). Coconut leaf beetle (Brontispa) in the Solomons. Alafua Agricul. Bull. 5: 17-22.

van Oosterhout C, Hutchinson W, Wills D and Shipley P (2004). Micro-Checker: software for identifying and correcting genotyping errors in microsatellite data. Mol. Ecol. Notes 4: 535-538.

Wilson JR, Dormontt EE, Prentis PJ, Lowe AJ, et al. (2009). Biogeographic concepts define invasion biology. Trends Ecol. Evol. 24: 586.

Wu H, Meng K and Zhu G (2008). Isolation and characterization of microsatellite markers in black muntjac (Muntiacus crinifrons). Mol. Ecol. Res. 8: 584-586. 